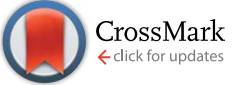

Cite this: RSC Adv., 2017, 7, 2115

\title{
Mandelic acid derived ionic liquids: synthesis, toxicity and biodegradability $\dagger$
}

\author{
Hannah Prydderch, ${ }^{a}$ Annette Hai $\beta,{ }^{b}$ Marcel Spulak, ${ }^{c}$ Brid Quilty, ${ }^{d}$ Klaus Kümmerer, ${ }^{b}$ \\ Andreas Heise ${ }^{e}$ and Nicholas Gathergood ${ }^{\star f}$
}

A series of ten ionic liquids (ILS) was synthesised from the renewable resource mandelic acid. The ILs showed low antimicrobial activity towards the thirteen bacterial and twelve fungal strains they were screened against. A general trend of increasing bacterial toxicity in the order methyl ester < ethyl ester < $n$-butyl ester/amide was observed. IL biodegradability was evaluated using the Closed Bottle test (OECD 301D). Biodegradation increased in the order of increasing alkyl chain length for the ester ILs (methyl < ethyl $<n$-butyl). Despite none of the ILs presenting as readily biodegradable ( $>60 \%$ in 28 days), a series of biodegradation transformation products has been proposed based on the degradation of the ester/ amide alkyl chain. This data has allowed for an assessment of the effect of IL structural features on toxicity and biodegradation, particularly allowing for a comparison to earlier work where additional oxygen atoms were present to facilitate biodegradation and attenuate toxicity. The mandelic acid derived ILs did not pass the Closed Bottle test (OECD 301D) and can be included in the rules of thumb for the design of biodegradable ILs.

Received 20th October 2016 Accepted 25th November 2016

DOI: $10.1039 / \mathrm{c} 6 \mathrm{ra} 25562 \mathrm{k}$

www.rsc.org/advances
There have been numerous efforts towards this aim with several works on the biodegradability and toxicity of ILs published since the early 2000 's. ${ }^{4-16}$

The utilisation of renewable resources for the synthesis of ILs has also been of great interest towards the aim of creating more sustainable ILs. Examples in the literature include the use of cholinium, ${ }^{17,18}$ prolinate, ${ }^{19}$ L-lactate ${ }^{20}$ and succinate; ${ }^{20}$ where low toxicity and readily biodegradable ILs from renewable resources have been identified. ${ }^{\mathbf{1 7}}$ More recently renewable pyridinium ILs have been synthesised from pyridinium zwitterions derived from amino acids and furfural. ${ }^{21}$

Mandelic acid is an aromatic $\alpha$-hydroxy acid that is found naturally in small quantities in plant tissues such as wheat leaves and grapes. ${ }^{22} \mathrm{~A}$ wide range of organisms (e.g. Penicillium chrysogenum $^{23}$ and phytoplankton ${ }^{24}$ ) can convert the naturally occurring compounds L-phenylalanine and phenyl acetic acid into mandelic acid. ${ }^{22}$ Mandelic acid can also be obtained by heating the glycoside amygdalin with concentrated hydrochloric acid. ${ }^{25}$ Amygdalin can be isolated from the seeds of the bitter almond tree ${ }^{26,27}$ and is also found in apricots ${ }^{27,28}$ and peach pits. ${ }^{22}$ In industry mandelic acid is made from the acid or enzyme catalysed hydrolysis of mandelonitrile. ${ }^{29}$ However, as mandelonitrile is often produced from the reaction between benzaldehyde and sodium cyanide, alternative methods avoiding the use of this toxic reagent to prepare mandelic acid and its derivatives have been developed. ${ }^{30}$ Optically pure $(R)$ and $(S)$-mandelic acid have also been produced from the renewable feedstock glucose using a genetically modified strain of E. coli. ${ }^{31}$ 
Studies on the toxicity of ILs that contain phenyl rings as an alternative to long alkyl chains have shown that it is possible to incorporate a lipophilic substructure into an IL whilst still maintaining low levels of toxicity. ${ }^{32,33}$ Colemen et al. ${ }^{34}$ and more recently Jordan et al. ${ }^{35}$ additionally showed that the introduction of a phenyl group in the form of phenylalanine in IL structures did not result in high levels of antimicrobial activity towards the bacterial or fungal strains screened, in the majority of cases. The impact of phenyl substitution was assessed in terms of IL cytotoxicity by Ranke et al. in $2007 .{ }^{33}$ Here the authors studied the influence of cation lipophilicity on IL cytotoxicity in IPC-81 leukemia cells and determined that lipophilicity was a dominating factor for IL cytotoxicity. Relatively low toxicity of the phenyl IL 1-methyl-3-(phenylmethyl)imidazolium chloride was demonstrated $\left(\mathrm{EC}_{50}>1000 \mu \mathrm{M}\right)$ compared to the 1-heptyl-3-methyl- $1 H$-imidazolium chloride (same number of carbons in cation side chain as the phenyl IL) $\left(\mathrm{EC}_{50}=399 \mu \mathrm{M}\right)$. The decrease in toxicity was attributed to the decrease in IL lipophilicity due to the presence of the phenyl group compared to the heptyl side chain. This result demonstrates that it is possible to attenuate IL cytotoxicity by replacing alkyl chains (e.g. heptyl) with phenyl groups. Ranke et al. also reported that decreasing the IL alkyl chain length from heptyl to $n$-butyl resulted in lower cytotoxicity (e.g. 1-butyl-3-methyl-1Himidazolium chloride, $\mathrm{EC}_{50}=3548 \mu \mathrm{M}$ ).

The introduction of aromatic rings can however have a marked effect on compound biodegradability (as determined from biodegradation in $\mathrm{CO}_{2}$ Headspace test ISO 14593), as in the case of Gore et al. where the introduction of benzyl groups significantly reduced IL biodegradability. ${ }^{36}$ In 2012 Coleman et al. showed that amino acid ILs containing phenyl rings can present as readily biodegradable. ${ }^{34}$ The assumption was that the aromatic ring of the phenylalanine moiety was converted to $\mathrm{CO}_{2}$, although no transformation product analysis was performed in that study to confirm this breakdown. More recently Jordan $e t ~ a l .{ }^{35}$ and Hai $\beta$ et $a l^{37}$ have further shown that a fully mineralisable IL can be produced from an amino acid (phenylalanine) IL containing an aromatic side chain. Although, the introduction of a phenyl group in the form of phenylalanine did not lead to a significant increase in biodegradation in all cases. This demonstrates the challenge of identifying "rules of thumb" 38 to assist in the design of biodegradable ILs. ${ }^{12,13}$

Previous work in the Gathergood group includes the design and synthesis of low toxicity ILs from mandelic acid derivatives. ${ }^{32}$ Herein we present a novel series of ILs synthesised directly from the renewable building block mandelic acid in a shorter and more efficient synthesis. Mandelic acid was selected as the backbone for the synthesis of the ILs as there are numerous reports in the literature detailing the microbial metabolic pathways for the degradation of mandelic acid and mandelates. ${ }^{22,39-42}$ Thus, by utilising a structural moiety susceptible to microbial breakdown we aim to better understand the ready biodegradability of the ILs.

It is desired that the ILs reported in the study will present with low toxicity similar to the previous class of mandelic acid derived ILs. ${ }^{32}$ By carrying out toxicity screening under the same conditions to the previously published work, a direct comparison of IL toxicity between the two series was possible. The study presented herein additionally expands on the previous work by providing an evaluation of the biodegradability of the newly synthesised ILs. Overall, this study aims to further investigate the effect of structural modifications on IL toxicity and biodegradation, in particular the effect on toxicity of removing oxygen from the previous class of ILs. This work intends to satisfy the $4^{\text {th }}, 7^{\text {th }}$ and $10^{\text {th }}$ principles of green chemistry: designing safer chemicals, the use of renewable feedstocks, and designing for degradation (respectively).

\section{Results and discussion}

\section{Synthesis}

A series of ten mandelic acid derived ILs (1-10) was synthesised with specifically designed structural motifs to allow for the investigation of their effect on toxicity and biodegradation (Fig. 1). These structural features included: three alkyl chain lengths, $n$-butyl, ethyl and methyl; both ester and amide moieties; the halide anion bromide; and various $\mathrm{N}$-heterocyclic headgroups, 1-methylimidazolium, pyridinium, 3-methoxy pyridinium and 3-(ethoxycarbonyl)pyridinium.

Other than the research carried out on this particular class of compounds directly preceding this work, ${ }^{32}$ there have been several mentions of this class of compounds in the literature. ${ }^{43-45}$ However, the only exact compound match for this new series that could be found in the literature was for the pyridinium ethyl ester IL (4), where compound characterisation could be found, but not biodegradation and toxicity analysis. ${ }^{46}$

All the ILs were synthesised as the racemate from the starting material DL-mandelic acid as both the $\mathrm{D}(-)$ and $\mathrm{L}(+)$ isomers are known to occur in nature. ${ }^{42}$ The synthesis of the ILs consisted of three steps (Schemes 1 and 2): esterification or amidation of mandelic acid; halogenation of the $\alpha$-position of the ester/ amide with thionyl bromide; and nucleophilic substitution of

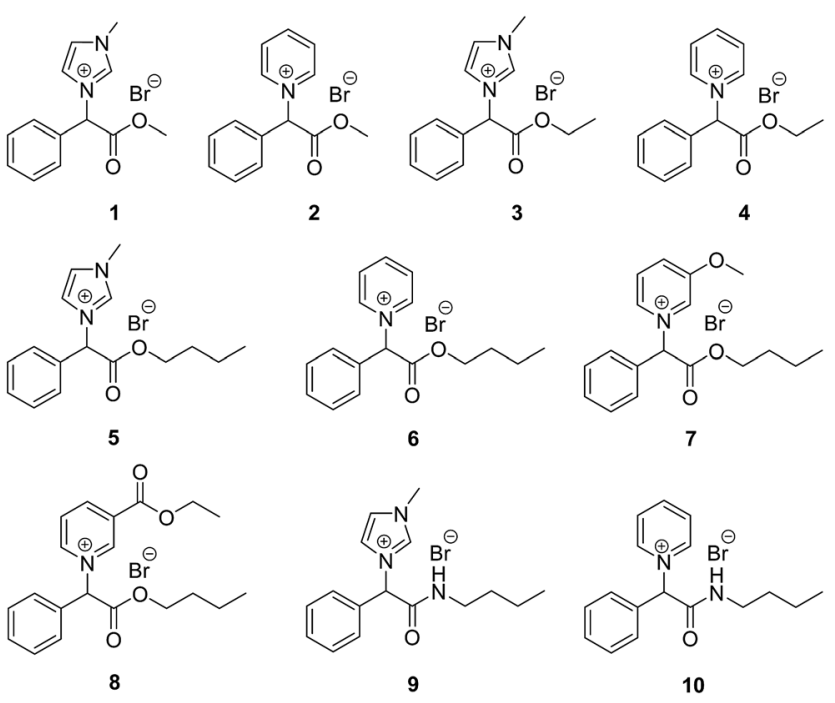

Fig. 1 Mandelic acid derived bromide ILs (1-10). 


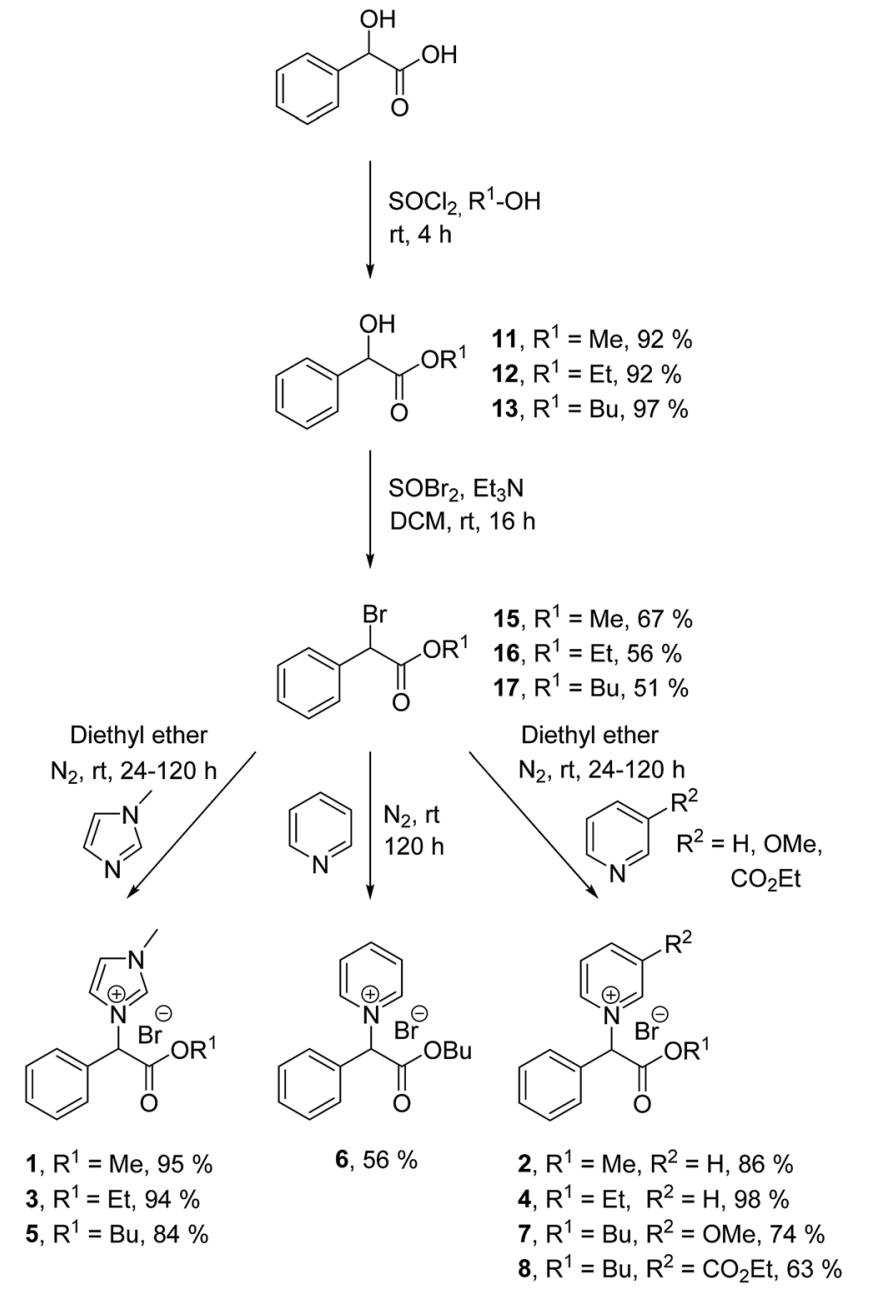

Scheme 1 General synthesis of mandelic acid derived ester ILs (1-8).

the $\alpha$-halo ester with an aromatic $\mathrm{N}$-heterocycle. The synthesis of the previously reported mandelic acid derived ILs required an additional synthetic step to produce the IL starting materials, as they were not synthesised directly from mandelic acid. ${ }^{32}$ Thus, the ILs described herein (1-10) were produced in a shorter and more efficient synthesis directly from the renewable resource. Additionally, mandelic acid production from benzaldehyde using sodium cyanide is avoided in this route by utilising the natural mandelate. ${ }^{30}$

Esterification of mandelic acid was carried out by the wellknown Fischer-Speier method ${ }^{47}$ to produce methyl, ethyl and $n$-butyl mandelic acid esters 11-13 (Scheme 1) in excellent yields (92-97\%). Modified literature procedures were employed for the synthesis of previously reported methyl ester $\mathbf{1 1}^{\mathbf{4 8}}$ and ethyl ester $12,{ }^{49}$ with a new procedure described for the synthesis of $n$-butyl ester $13^{50}$ (see ESI†). The $n$-butyl amide $\mathbf{1 4}$ (Scheme 2) was synthesised with acetyl chloride (AcCl), according to a modified version of the literature procedure, ${ }^{51}$ in high yield (89\%) (see ESI $\dagger$ ). Initial attempts to synthesise $\mathbf{1 4}$ by greener methods did not proceed in high yields $(<9 \%))^{52,53}$

Synthesis of the $\alpha$-bromoester and $\alpha$-bromoamide alkylating agents 15-18 (Schemes 1 and 2) were carried out by addition of<smiles>O=C(O)C(O)c1ccccc1</smiles>

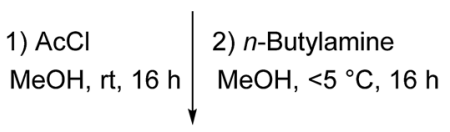<smiles>CCCCNC(=O)C(O)c1ccccc1</smiles>

$14,89 \%$ $\mathrm{SOBr}_{2}, \mathrm{Et}_{3} \mathrm{~N}$ DCM, rt, $16 \mathrm{~h}$<smiles>CCCCCNC(=O)C(Br)c1ccccc1</smiles>

$18,52 \%$



9, $99 \%$
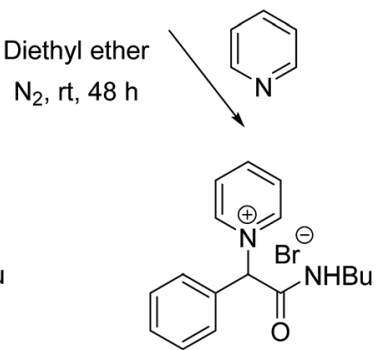

$10,86 \%$
Scheme 2 General synthesis of mandelic acid derived amide ILs (9 and 10).

thionyl bromide $\left(\mathrm{SOBr}_{2}\right)$ to the mandelic acid esters 11-13 and amide 14. The reaction occurs via a meso substitution of the alcohol by bromine and was utilised to give alkylating agents 15-18 (Schemes 1 and 2) in moderate yields (51-67\%). Previously reported $\alpha$-bromoester $\mathbf{1 5}$ was synthesised by a modification of the literature procedure, ${ }^{54}$ with a new procedure described for $\alpha$-bromoester $16^{55}$ (see ESI $\dagger$ ).

ILs 1-10 (Schemes 1 and 2) were synthesised via a nucleophilic substitution reaction between an N-heterocycle and the $\alpha$ bromoester/ $\alpha$-bromoamide of mandelic acid (15-18) (see ESI $\dagger$ ). $\mathrm{N}$-heterocycles 1-methylimidazole, pyridine, 3-methoxy pyridine and ethyl nicotinate (required for the 3-(ethoxycarbonyl)pyridinium headgroup) were selected for the IL synthesis. Previously reported IL $\mathbf{4}^{46}$ was prepared according to a new synthetic procedure (see ESI $\dagger$ ).

Seven of the ILs (1-5, 9 and 10) were produced in excellent yields (84-99\%), with the three $n$-butyl esters with pyridinium (6), 3-methoxy pyridinium (7) and 3-(ethoxycarbonyl)pyridinium (8) headgroups produced in moderate yields $(56,74$ and $63 \%$ respectively). All ten ILs were obtained as crystalline solids with a wide range of melting points observed $\left(48-169^{\circ} \mathrm{C}\right.$ ) (see ESI $\dagger$ ). At the COIL-6 conference in South Korea, Professor Kenneth 
Table 1 Antifungal screening results for ILs 1-10 (MIC, IC $C_{80}$ or $\left.I C_{50}\right)$

\begin{tabular}{|c|c|c|c|c|c|}
\hline \multirow[b]{2}{*}{ Strain $^{a}$} & \multirow[b]{2}{*}{ Time (h) } & \multicolumn{4}{|c|}{$\mathrm{IL} \mathrm{MIC}^{b}(\mathrm{mM})$} \\
\hline & & $1,8,9,10$ & $2,4,7$ & 3 & 5,6 \\
\hline \multirow[t]{2}{*}{ CA1 } & $24 \mathrm{~h}$ & $>2.0$ & $>1.0$ & $>2.0$ & $>2.0$ \\
\hline & $48 \mathrm{~h}$ & $>2.0$ & $>1.0$ & $>2.0$ & $>2.0$ \\
\hline \multirow[t]{2}{*}{$\mathrm{CA} 2$} & $24 \mathrm{~h}$ & $>2.0$ & $>1.0$ & $>2.0$ & $>2.0$ \\
\hline & $48 \mathrm{~h}$ & $>2.0$ & $>1.0$ & $>2.0$ & $>2.0$ \\
\hline \multirow[t]{2}{*}{$\mathrm{CP}$} & $24 \mathrm{~h}$ & $>2.0$ & $>1.0$ & $>2.0$ & $>2.0$ \\
\hline & $48 \mathrm{~h}$ & $>2.0$ & $>1.0$ & $>2.0$ & $>2.0$ \\
\hline \multirow[t]{2}{*}{ CK1 } & $24 \mathrm{~h}$ & $>2.0$ & $>1.0$ & 0.5 & $>2.0$ \\
\hline & $48 \mathrm{~h}$ & $>2.0$ & $>1.0$ & 0.5 & $>2.0$ \\
\hline \multirow[t]{2}{*}{$\mathrm{CK} 2$} & $24 \mathrm{~h}$ & $>2.0$ & $>1.0$ & 1.0 & $>2.0$ \\
\hline & $48 \mathrm{~h}$ & $>2.0$ & $>1.0$ & 1.0 & $>2.0$ \\
\hline \multirow[t]{2}{*}{$\mathrm{CT}$} & $24 \mathrm{~h}$ & $>2.0$ & $>1.0$ & $>2.0$ & 2.0 \\
\hline & $48 \mathrm{~h}$ & $>2.0$ & $>1.0$ & $>2.0$ & $>2.0$ \\
\hline \multirow[t]{2}{*}{ CG } & $24 \mathrm{~h}$ & $>2.0$ & $>1.0$ & $>2.0$ & $>2.0$ \\
\hline & $48 \mathrm{~h}$ & $>2.0$ & $>1.0$ & $>2.0$ & $>2.0$ \\
\hline \multirow[t]{2}{*}{ CL } & $24 \mathrm{~h}$ & $>2.0$ & $>1.0$ & $>2.0$ & $>2.0$ \\
\hline & $48 \mathrm{~h}$ & $>2.0$ & $>1.0$ & $>2.0$ & $>2.0$ \\
\hline \multirow[t]{2}{*}{$\mathrm{TA}$} & $24 \mathrm{~h}$ & $>2.0$ & $>1.0$ & $>2.0$ & $>2.0$ \\
\hline & $48 \mathrm{~h}$ & $>2.0$ & $>1.0$ & $>2.0$ & $>2.0$ \\
\hline \multirow[t]{2}{*}{$\mathrm{AF}$} & $24 \mathrm{~h}$ & $>2.0$ & $>1.0$ & $>2.0$ & $>2.0$ \\
\hline & $48 \mathrm{~h}$ & $>2.0$ & $>1.0$ & $>2.0$ & $>2.0$ \\
\hline \multirow[t]{2}{*}{$\mathrm{AC}$} & $24 \mathrm{~h}$ & $>2.0$ & $>1.0$ & $>2.0$ & $>2.0$ \\
\hline & $48 \mathrm{~h}$ & $>2.0$ & $>1.0$ & $>2.0$ & $>2.0$ \\
\hline \multirow[t]{2}{*}{$\mathrm{TM}$} & $72 \mathrm{~h}$ & $>2.0$ & $>1.0$ & $>2.0$ & $>2.0$ \\
\hline & $120 \mathrm{~h}$ & $>2.0$ & $>1.0$ & $>2.0$ & $>2.0$ \\
\hline \multicolumn{6}{|c|}{$\begin{array}{l}{ }^{a} \text { CA1: Candida albicans ATCC 44859, CA2: Candida albicans ATCC } \\
\text { 90028, CP: Candida parapsilosis ATCC 22019, CK1: Candida kruse } \\
\text { ATCC 6258, CK2: Candida krusei E28, CT: Candida tropicalis } 156 \text {, CG } \\
\text { Candida glabrata 20/I, CL: Candida lusitaniae } 2446 / \mathrm{I} \text {, TA: Trichosporon } \\
\text { asahii 1188, AF: Aspergillus fumigatus } 231 \text {, AC: Absidia corymbifera } 272 \\
\text { TM: Trichophyton mentagrophytes } 445 .{ }^{b} \text { IC }_{50} \text { values were assessed for } \\
\text { AF, AC and TM and } \mathrm{IC}_{80} \text { for all other strains. }\end{array}$} \\
\hline
\end{tabular}

Seddon proposed that the arbitrary use of $100{ }^{\circ} \mathrm{C}$ as a melting point cut-off for the definition of an IL was inflexible and constraining and should no longer be used as a prerequisite for classification as an IL. ${ }^{56}$ Thus, the terminology of IL is used herein despite the majority of the ILs described possessing melting points $>100{ }^{\circ} \mathrm{C}$. ILs 1 and 6 had the lowest melting points (61-63 and $48-50{ }^{\circ} \mathrm{C}$ respectively) despite any similar structural features. The highest melting points for the series were observed for the pyridinium ILs 4 and 10 (161-162 and $167-169^{\circ} \mathrm{C}$ respectively). ILs 2 and 9 had melting points around $140{ }^{\circ} \mathrm{C}$ (140-142 and $143-145{ }^{\circ} \mathrm{C}$ respectively), again with no similar structural features. ILs 3 and 5 had melting points around $100{ }^{\circ} \mathrm{C}$ (101-102 and 99-101 ${ }^{\circ} \mathrm{C}$ respectively), both with 1-methylimidazolium headgroups. ILs 7 and 8 had moderately high melting points (127-128 and $112-113{ }^{\circ} \mathrm{C}$ respectively), both $n$-butyl esters with 3-methoxy pyridinium and 3-(ethoxycarbonyl)pyridinium headgroups respectively. It is observed that the class of headgroup has a more marked effect on the IL melting points than the alkyl chain length. In all but one case the pyridinium ILs had higher melting points than the 1methylimidazolium ILs with the same ester/amide alkyl chain, with this trend only reversed for the $n$-butyl ester ILs 5 and $\mathbf{6}$. The $n$-butyl amides ILs $\mathbf{9}$ and $\mathbf{1 0}$ had higher melting points than the $n$-butyl ester ILs, which is expected due to their additional hydrogen bond donor ability.

\section{Microbial toxicity screening}

Our strategy regarding toxicity screening of chemicals as part of a tandem toxicity and biodegradation assessment has been previously published. ${ }^{34-37}$ One reason a compound can fail a biodegradation test is due to high toxicity to critical microorganisms in the inoculum required for breakdown. For instance, previous studies have shown that high toxicity to bacteria, e.g. Pseudomonas putida, can be linked to inhibited biodegradation. ${ }^{57}$ Thus, completing a microbial toxicity study prior to biodegradation screening provides valuable data to assist analysis of biodegradation results. Compounds are first evaluated against twenty bacterial and fungal strains to identify high antimicrobial activity examples. Secondly, $\mathrm{IC}_{50}$ values at higher IL concentrations are measured for compounds which do not exhibit high antimicrobial activity. Compounds which have high antimicrobial activity are identified as 'hit' compounds as part of our group's medicinal chemistry and biocide research interests. Low antimicrobial activity compounds are prioritised for green chemistry applications.

\section{Fungal toxicity results}

The in vitro antifungal activities of ILs 1-10 (Table 1) were evaluated against four ATCC strains (Candida albicans ATCC 44859, Candida albicans ATCC 90028, Candida parapsilosis ATCC 22019, Candida krusei ATCC 6258) and eight clinical isolates of fungi, five yeasts (Candida krusei E28, Candida tropicalis 156, Candida glabrata 20/I, Candida lusitaniae 2446/I, Trichosporon asahii 1188) and three filamentous fungi (Aspergillus fumigatus 231, Absidia corymbifera 272, Trichophyton mentagrophytes 445). Three ATCC strains were also used as the quality control strains. All the isolates were maintained on Sabouraud dextrose agar prior to being tested. Minimum inhibitory concentrations (MICs) were determined by modified CLSI standard of the microdilution format of the M27-A3 ${ }^{58}$ and M38-A2 ${ }^{59}$ documents for yeasts and filamentous fungi respectively. MIC values were calculated after 72 and $120 \mathrm{~h}$ for $T$. mentagrophytes, and for all other strains MIC values were calculated after 24 and $48 \mathrm{~h}$. The MICs were defined as 50\% inhibition $\left(\mathrm{IC}_{50}\right)$ of the control growth for yeasts or $80 \%$ inhibition $\left(\mathrm{IC}_{80}\right)$ of the control growth for filamentous fungi. The maximum test concentration of the IL was dependant on the IL aqueous solubility, with the highest IL concentration in the test being $2.0 \mathrm{mM}$. See ESI $\dagger$ for full experimental details.

The results from Table 1 show that the 1-methylimidazolium methyl ester IL (1), the 3-(ethoxycarbonyl)pyridinium $n$-butyl ester IL (8) and the 1-methylimidazolium and pyridinium $n$ butyl amide ILs (9 and 10) did not have high fungal toxicity, up to the maximum IL concentration limit, with $\mathrm{IC}_{50} / \mathrm{IC}_{80}$ values $>2.0 \mathrm{mM}$. The pyridinium methyl and ethyl ester ILs ( 2 and 4 ) and the 3-methoxy pyridinium $n$-butyl ester IL (7) did not have high toxicity, up to the maximum IL concentration limit, with $\mathrm{IC}_{50} / \mathrm{IC}_{80}$ values $>1.0 \mathrm{mM}$. The 1 -methylimidazolium and pyridinium $n$-butyl ester ILs (5 and 6) inhibited C. tropicalis at 
<smiles></smiles>

$19^{32}$

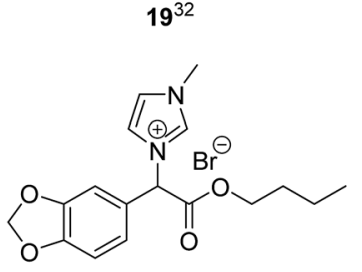

$21^{32}$

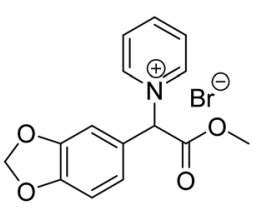

$20^{32}$

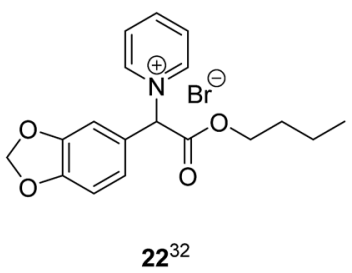

Fig. 2 Mandelic acid derived ILs 19-20.32

$2.0 \mathrm{mM}$ after $24 \mathrm{~h}$ but showed no inhibition up to the test concentration of $2.0 \mathrm{mM}$ after $48 \mathrm{~h}$, suggesting that the fungal strain was able to overcome the initial observed inhibition at $2.0 \mathrm{mM}$ after $24 \mathrm{~h}$ and recover. However, this result is not significant when compared to other data in Table 1, especially as it appears for only one fungal strain. The concentration is also well above the level used in the biodegradation studies. The overall findings are that none of the ILs demonstrated high toxicity to the range of fungal strains screened against. The 1methylimidazolium ethyl ester IL (3) inhibited C. krusei ATCC 6258 at $0.50 \mathrm{mM}$ after both 24 and $48 \mathrm{~h}$, and C. krusei E28 at $1.0 \mathrm{mM}$ after both 24 and $48 \mathrm{~h}$. Higher levels of fungal toxicity are usually observed as the length of the alkyl chain increases. ${ }^{7}$ Although it is unexpected that the ethyl ester IL (3) is more toxic that the $n$-butyl analogue (5), one must be careful not to overinterpret the data based on two compounds. High toxicity was not observed for the mandelic acid derived ILs (1-10) in this screening, which is a significant result for the design of safer ILs. As no compounds with high fungal toxicity were found, all were classed as suitable substrates for biodegradation screening based on fungal toxicity data.

Previous work evaluated the antifungal activity of a series of mandelic acid derived ILs similar to those described herein, but which incorporated a higher oxygen content (e.g. ether, phenol and catechol groups are present). ${ }^{60,61}$ When comparing the $\mathrm{IC}_{80}$ or $\mathrm{IC}_{50}$ values of the 1-methylimidazolium and pyridinium methyl and $n$-butyl ester ILs $(\mathbf{1}, \mathbf{2}, \mathbf{5}$ and $\mathbf{6})$ (Table 1) to the mandelic acid derived ILs previously published with the same ester alkyl chain length and headgroup ${ }^{32}$ (19-22) (Fig. 2), only IL 1 had the same low level of inhibition as the previous ILs (1922) with no high toxicity up to the maximum IL concentration limit $\left(\mathrm{IC}_{50} / \mathrm{IC}_{80}>2.0 \mathrm{mM}\right)^{60,61}$ (Table $\left.\mathrm{S} 1 \dagger\right)$. This result is not surprising as a lower level of inhibition is expected for the previous ILs (19-22) due to the presence of the oxygen functionality on the aromatic ring which decreases IL lipophilicity, increases IL hydrophilicity, and in turn decreases IL toxicity. ${ }^{62}$ However, despite a higher fungal toxicity observed for the new ILs $(\mathbf{1}, \mathbf{2}, \mathbf{5}$ and $\mathbf{6})$ the results herein do not represent a large increase in the level of inhibition compared to the previously published ILs (19-22). IL 19 has been included here for
Table 2 Antibacterial screening results for ILs 1-10 (MIC, IC 95$)$

\begin{tabular}{|c|c|c|c|c|c|c|c|c|c|}
\hline \multirow[b]{2}{*}{$\operatorname{Strain}^{a}$} & \multirow[b]{2}{*}{ Time (h) } & \multicolumn{8}{|c|}{ IL MIC (mM) } \\
\hline & & 1 & 2,8 & 3 & 4,7 & 5 & 6 & 9 & 10 \\
\hline \multirow[t]{2}{*}{ SA } & $24 \mathrm{~h}$ & 2.0 & $>2.0$ & 0.50 & $>1.0$ & 2.0 & 0.50 & $>2.0$ & 2.0 \\
\hline & $48 \mathrm{~h}$ & 2.0 & $>2.0$ & 0.50 & $>1.0$ & $>2.0$ & 2.0 & $>2.0$ & 2.0 \\
\hline \multirow[t]{2}{*}{ MRSA } & $24 \mathrm{~h}$ & $>2.0$ & $>2.0$ & 0.50 & $>1.0$ & $>2.0$ & 2.0 & $>2.0$ & $>2.0$ \\
\hline & $48 \mathrm{~h}$ & $>2.0$ & $>2.0$ & 0.50 & $>1.0$ & $>2.0$ & $>2.0$ & $>2.0$ & $>2.0$ \\
\hline \multirow[t]{2}{*}{ SE } & $24 \mathrm{~h}$ & 2.0 & 2.0 & 0.25 & $>1.0$ & 2.0 & 0.50 & $>2.0$ & 2.0 \\
\hline & $48 \mathrm{~h}$ & 2.0 & 2.0 & 0.25 & $>1.0$ & $>2.0$ & 1.0 & $>2.0$ & 2.0 \\
\hline \multirow[t]{2}{*}{$\mathrm{EF}$} & $24 \mathrm{~h}$ & $>2.0$ & $>2.0$ & 0.50 & $>1.0$ & $>2.0$ & $>2.0$ & $>2.0$ & $>2.0$ \\
\hline & $48 \mathrm{~h}$ & $>2.0$ & $>2.0$ & 0.50 & $>1.0$ & $>2.0$ & $>2.0$ & $>2.0$ & $>2.0$ \\
\hline \multirow[t]{2}{*}{$\mathrm{EC}$} & $24 \mathrm{~h}$ & $>2.0$ & $>2.0$ & 2.0 & $>1.0$ & $>2.0$ & $>2.0$ & $>2.0$ & $>2.0$ \\
\hline & $48 \mathrm{~h}$ & $>2.0$ & $>2.0$ & 2.0 & $>1.0$ & $>2.0$ & $>2.0$ & $>2.0$ & $>2.0$ \\
\hline \multirow[t]{2}{*}{ KP } & $24 \mathrm{~h}$ & $>2.0$ & $>2.0$ & 2.0 & $>1.0$ & $>2.0$ & $>2.0$ & $>2.0$ & $>2.0$ \\
\hline & $48 \mathrm{~h}$ & $>2.0$ & $>2.0$ & 2.0 & $>1.0$ & $>2.0$ & $>2.0$ & $>2.0$ & $>2.0$ \\
\hline \multirow[t]{2}{*}{ KP-E } & $24 \mathrm{~h}$ & 2.0 & $>2.0$ & 1.0 & $>1.0$ & 1.0 & $>2.0$ & $>2.0$ & $>2.0$ \\
\hline & $48 \mathrm{~h}$ & 2.0 & $>2.0$ & 1.0 & $>1.0$ & $>2.0$ & $>2.0$ & $>2.0$ & $>2.0$ \\
\hline \multirow[t]{2}{*}{ PA } & $24 \mathrm{~h}$ & $>2.0$ & $>2.0$ & $>2.0$ & $>1.0$ & $>2.0$ & $>2.0$ & $>2.0$ & $>2.0$ \\
\hline & $48 \mathrm{~h}$ & $>2.0$ & $>2.0$ & $>2.0$ & $>1.0$ & $>2.0$ & $>2.0$ & $>2.0$ & $>2.0$ \\
\hline
\end{tabular}

${ }^{a}$ SA: Staphylococcus aureus ATTC 6538, EC: Escherichia coli ATTC 8739, PA: Pseudomonas aeruginosa ATTC 9027, MRSA: Staphylococcus aureus MRSA HK5996/08, SE: Staphylococcus epidermidis HK6966/08, EF: Enterococcus sp. HK14365/08, KP: Klebsiella pneumoniae HK11750/08, KP-E: Klebsiella pneumoniae ESBL HK14368/08.

comparative purposes despite containing a chloride anion, as the halide anions bromide and chloride have previously been reported to have similar toxic effects in imidazolium ILs. ${ }^{63}$

\section{Bacterial toxicity results}

The in vitro antibacterial activities of ILs 1-10 (Table 2) were evaluated against three ATTC strains (Staphylococcus aureus ATTC 6538, Escherichia coli ATTC 8739, Pseudomonas aeruginosa ATTC 9027) and five clinical isolates (Staphylococcus aureus MRSA HK5996/08, Staphylococcus epidermidis HK6966/08, Enterococcus sp. HK14365/08, Klebsiella pneumoniae HK11750/ 08, Klebsiella pneumoniae ESBL HK14368/08). The ATCC strains were also used as the quality control strains. MIC values were calculated after 24 and $48 \mathrm{~h}$. The MICs were defined as $95 \%$ inhibition $\left(\mathrm{IC}_{95}\right)$ of the control growth. The maximum test concentration of the IL was dependant on the IL aqueous solubility, with the highest IL concentration in the test being $2.0 \mathrm{mM}$. All the isolates were maintained on Mueller-Hinton dextrose agar prior to being tested. See ESI $\dagger$ for full experimental details.

The results from Table 2 show that the ILs 1, 2, 4 and 7-10 did not have high toxicity towards the bacterial strains screened against. The pyridinium ethyl ester IL (4) and the 3-methoxy pyridinium $n$-butyl ester (7) did not have high toxicity, up to the IL maximum concentration limit, with $\mathrm{IC}_{95}$ values $>1.0 \mathrm{mM}$. The 1-methylimidazolium $n$-butyl amide IL (9) did not have high toxicity, up to the IL maximum concentration limit, with $\mathrm{IC}_{95}$ values $>2.0 \mathrm{mM}$. The 1 -methylimidazolium and pyridinium methyl ester ILs (1 and 2), the 3-methoxy pyridinium $n$-butyl ester IL (8) and the pyridinium $n$-butyl amide IL (10) all inhibited S. epidermidis at a concentration of $2.0 \mathrm{mM}$, with IL 10 
additionally inhibiting $S$. aureus at $2.0 \mathrm{mM}$ and IL 1 additionally inhibiting $S$. aureus and $K$. pneumoniae ESBL at $2.0 \mathrm{mM}$. Overall, the results for ILs 1, 2 and 8-10 are not significantly different. The 1-methylimidazolium $n$-butyl ester IL (5) inhibited $S$. aureus and $S$. epidermidis at $2.0 \mathrm{mM}$ and $K$. pneumoniae ESBL at $1.0 \mathrm{mM}$ after $24 \mathrm{~h}$, but after $48 \mathrm{~h}$ no longer inhibited $S$. aureus, $S$. epidermidis and $K$. pneumoniae ESBL up to the test concentration of $2.0 \mathrm{mM}$, suggesting that the bacterial strains were able to overcome the initial observed inhibition after $24 \mathrm{~h}$ and recover. The pyridinium $n$-butyl ester IL (6) inhibited $S$. aureus MRSA at $2.0 \mathrm{mM}$ after $24 \mathrm{~h}$, but after $48 \mathrm{~h}$ no longer inhibited $S$. aureus MRSA up to the test concentration of $2.0 \mathrm{mM}$. IL 6 also inhibited $S$. aureus and $S$. epidermidis at $0.50 \mathrm{mM}$ after $24 \mathrm{~h}$, which reduced to inhibition at $2.0 \mathrm{mM}$ to $S$. aureus and $1.0 \mathrm{mM}$ to $S$. epidermidis after $48 \mathrm{~h}$. The 1-methylimidazolium ethyl ester IL (3) showed the greatest level of inhibition to the bacterial strains across the board with the highest level of inhibition observed against $S$. epidermidis $\left(\mathrm{IC}_{95}=0.25 \mathrm{mM}\right)$ and against $S$. aureus, $S$. aureus MRSA and Enterococcus $\mathrm{sp}$. $\left(\mathrm{IC}_{95}=0.50 \mathrm{mM}\right)$. ILs 3 and 6 generally showed greater inhibition towards the Gram-positive bacterial strains (S. aureus, S. aureus MRSA, S. epidermidis and Enterococcus sp.) than towards the Gram-negative bacterial strains (E. coli, $K$. pneumoniae, $K$. pneumoniae ESBL and $P$. aeruginosa). This observation is most pronounced for IL 3, where the greatest level of inhibition of a Gram-negative bacterial strain was observed against $K$. pneumoniae ESBL $\left(\mathrm{IC}_{95}=0.50 \mathrm{mM}\right)$. The greatest level of inhibition by IL 3 for a Gram-positive bacterial strain was observed against $S$. epidermidis $\left(\mathrm{IC}_{95}=0.25 \mathrm{mM}\right)$; however, this is a much higher concentration than used in the biodegradation testing (CBT). The overall findings of this work show that none of the ILs demonstrated high toxicity to the range of bacterial strains screened. IL 3 presented with the highest toxicity; however, this was still only observed as moderate toxicity against several bacterial strains.
In all cases the previously synthesised mandelic acid derived $\operatorname{ILs}^{32}$ (19-22) (Fig. 2) had lower levels of inhibition than the new ILs with the same ester alkyl chain length and headgroup (1, 2, 5 and 6) for every bacterial strain that was screened against, with no high toxicity observed up to the maximum IL concentration limit $\left(\mathrm{IC}_{95}\right.$ values $>2.0 \mathrm{mM}$ ) (Table S2 $\left.\dagger\right) .{ }^{\mathbf{6 0}, 61}$ Despite a higher bacterial toxicity observed for the new ILs (1, 2, 5 and 6), the results presented herein ( $\mathrm{IC}_{95}$ values in the range $0.50-2.0 \mathrm{mM}$ ) do not represent a large increase in the level of inhibition. This is a significant positive result considering the new class of ILs are synthesised directly from a renewable resource in a shorter and more efficient synthesis.

The antibacterial activities of ILs 1-10 were also evaluated against one Gram-positive bacterial strain (Bacillus subtilis DSMZ 10) and four Gram-negative bacteria (Escherichia coli DSMZ 498, Pseudomonas fluorescens DSMZ 50090, Pseudomonas putida CP1, and Pseudomonas putida KT 2440). Of note, the Pseudomonas strains have been reported as important for biodegradation. ${ }^{57,64}$ The bacterial toxicity of the ILs was determined by bacterial growth inhibition in a 24 hour assay and are expressed as $\mathrm{IC}_{50}$ values. Stock solutions of the ILs were prepared in deionised water to a maximum concentration of $2000 \mathrm{mM}$. The concentration of each stock solution was determined by the maximum aqueous solubility of each IL (Table S3†). ILs 2, 4, 7 and 9 had a solubility limit lower than $2000 \mathrm{mM}$. The maximum test concentration of each IL was a factor of 10 dilution of the IL stock solution. All the toxicity tests were carried out in triplicate. See ESI $\dagger$ for full experimental details.

The results from Table 3 show that the majority of the ILs have low toxicity $\left(\mathrm{IC}_{50}\right.$ values $>25-50 \mathrm{mM}$ ) towards the bacterial strains screened against, with the lowest toxicity observed for the pyridinium ethyl ester IL (4) against $P$. putida $\mathrm{KT} 2440\left(\mathrm{IC}_{50}>\right.$ $100 \mathrm{mM}$ ). The highest levels of inhibition were observed for the 1-methylimidazolium $n$-butyl ester IL (5) which inhibited $E$. coli and $P$. putida CP1 with $\mathrm{IC}_{50}$ values of $6.25-12.5 \mathrm{mM}$, the $n$-butyl

Table 3 Antibacterial screening results for ILs 1-10 and 19-22 (IC 50$)$

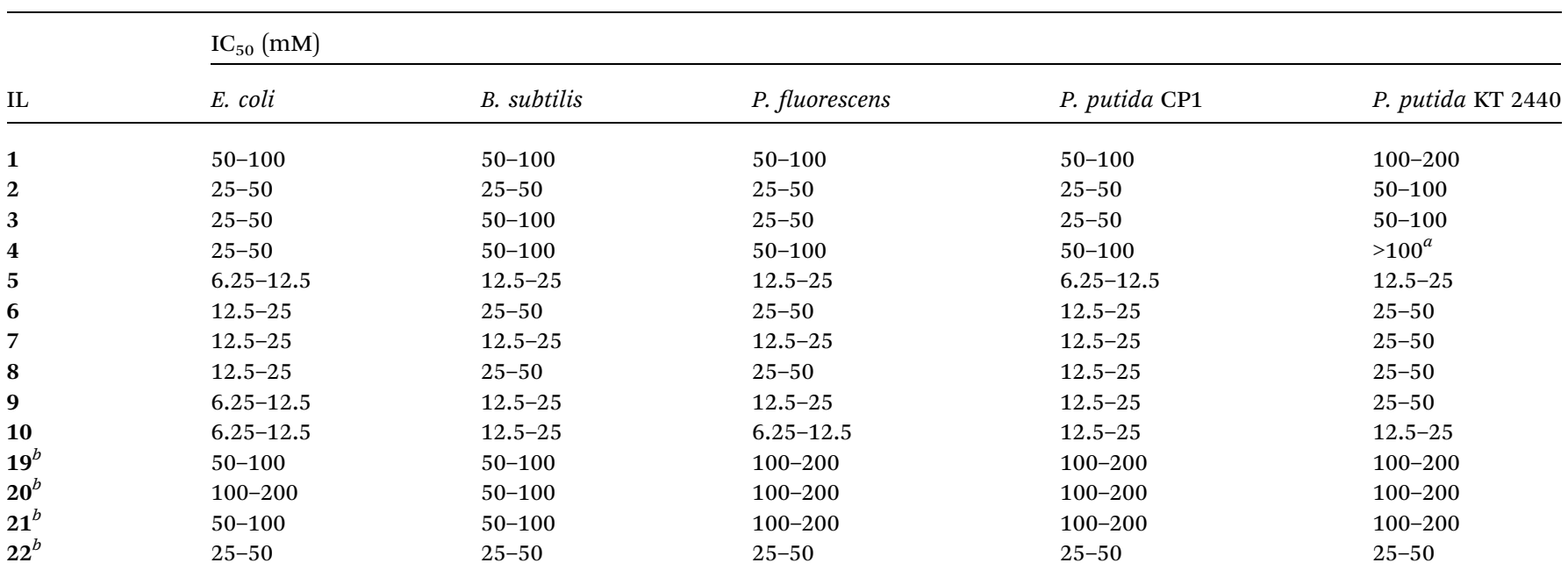

${ }^{a}$ Solubility limit; $\mathrm{IC}_{50}$ value greater than solubility in media. ${ }^{b}$ Previously reported in ref. 32 . Bacillus subtilis DSMZ 10 (B. subtilis), Escherichia coli DSMZ 498 (E. coli), Pseudomonas fluorescens DSMZ 27050090 (P. fluorescence), Pseudomonas putida CP1 (P. putida CP1), Pseudomonas putida KT2440 (P. putida KT2440). 
Table 4 Calculation of theoretical ester/amide biodegradation for ILs 1-10 with a comparison to the experimental results obtained in the CBT (OECD 301D) after 28 days

\begin{tabular}{|c|c|c|c|c|c|}
\hline IL & $\begin{array}{l}\text { Total carbon } \\
\text { number }\end{array}$ & $\begin{array}{l}\text { Ester/amide carbon } \\
\text { number }\end{array}$ & $\begin{array}{l}\text { Theoretical biodegradation due to } \\
\text { share of carbon in side chain (\%) }\end{array}$ & $\begin{array}{l}\text { Experimental } \\
\text { biodegradation (\%) }\end{array}$ & $\begin{array}{l}\text { Absolute } \\
\text { difference (\%) }\end{array}$ \\
\hline 1 & 13 & 1 & 8 & 5 & +3 \\
\hline 3 & 14 & 2 & 14 & 20 & -6 \\
\hline 4 & 15 & 2 & 13 & 16 & -3 \\
\hline 5 & 16 & 4 & 25 & 27 & -2 \\
\hline 8 & 20 & 6 & 30 & 31 & -1 \\
\hline 9 & 16 & 4 & 25 & 0 & +25 \\
\hline 10 & 17 & 4 & 24 & 1 & +22 \\
\hline
\end{tabular}

amide pyridinium IL (10) which inhibited E. coli and P. fluorescens with $\mathrm{IC}_{50}$ values of $6.25-12.5 \mathrm{mM}$, and the 1-methylimidazolium $n$-butyl amide (9) which inhibited $E$. coli with $\mathrm{IC}_{50}$ values of 6.25-12.5 mM. A general trend of increasing IL toxicity with increasing alkyl chain length was observed across all bacterial strains in the order methyl ester $<$ ethyl ester $<n$-butyl ester/amide. In general the methyl ester ILs 1 and $\mathbf{2}$ had lower toxicity $\left(\mathrm{IC}_{50}=25-200 \mathrm{mM}\right)$ than the ethyl ester ILs 3 and $\mathbf{4}\left(\mathrm{IC}_{50}\right.$ $=25-100 \mathrm{mM}$ ), which in turn had lower toxicity than the $n$-butyl ester/amide ILs 5-8 $\left(\mathrm{IC}_{50}=6.25-50 \mathrm{mM}\right)$. This observed trend is expected as the literature shows increasing the length of alkyl groups of ILs leads to higher antimicrobial activity. ${ }^{7}$ This is also consistent with microbial toxicity data for linear alkylbenzene sulfonates and quaternary ammonium compounds. ${ }^{65,66}$ ILs with longer alkyl chains have a higher lipophilicity, which increases their ability to derange/interact or permeate through the bacterial cell membrane and disrupt it leading ultimately to cell death. ${ }^{62,67}$ IL 3 did not present with the same inhibition towards E. coli $\left(\mathrm{IC}_{50}=25-50 \mathrm{mM}\right)$ as observed in the previous bacterial toxicity run ( $\mathrm{IC}_{95}=2 \mathrm{mM}$ ) (Table 2), which is attributed to two different strains of $E$. coli used. There was no observed trend for the level of bacterial inhibition between 1-methylimidazolium ILs and pyridinium ILs across the various alkyl chain lengths. When comparing the $\mathrm{IC}_{50}$ values of the $n$-butyl ester ILs with pyridinium (6), 3-methoxy pyridinium (7) and 3-(ethoxycarbonyl)pyridinium (8) headgroups, a difference in the inhibition was only observed for IL 7, which showed the same increase in inhibition towards B. subtilis and P. fluorescens $\left(\mathrm{IC}_{50}=12.5-25 \mathrm{mM}\right)$. When comparing the inhibition of the Gram-positive bacteria $E$. coli with the Gram-negative bacteria B. subtilis, seven ILs (3-6 and 8-10) inhibited $E$. coli to a greater extent than B. subtilis. The remaining ILs (1, 2 and 7) inhibited both $E$. coli and B. subtilis to the same extent. High susceptibility of Gram-positive bacteria over Gram-negative bacteria has previously been highlighted in the literature and has been linked to IL lipophilicity. ${ }^{16}$

When comparing the $\mathrm{IC}_{50}$ values of the 1-methylimidazolium and pyridinium methyl and $n$-butyl ester ILs (1, 2, 5 and 6) to the mandelic acid derived ILs previously published with the same ester alkyl chain length and headgroup ${ }^{32}$ (19-22) (Fig. 2 and Table 3), in all cases the previous class of ILs had lower levels of inhibition towards each bacterial strain that was screened against. Despite the maximum inhibition for the previous class being lower than the new class (highest toxicity, $\mathrm{IC}_{50}=25-50 \mathrm{mM}$ for IL 22 across all bacterial strains), it is a significant positive result that the new class of ILs do not represent a large increase in the level of inhibition (highest toxicity, $\mathrm{IC}_{50}=6.25-12.5 \mathrm{mM}$ for IL 5, 10 and 9 to several bacterial strains).

The microbial toxicity of the mandelic acid derived ILs 1-10 is clearly influenced by the lipophilicity of the IL structures. An increase in microbial toxicity over the previous class of mandelic acid derived ILs (19-22) is observed due to the removal of the phenyl ring substitution and subsequent increase in IL lipophilicity. It has been shown in the literature that decreasing the lipophilicity of imidazolium ILs by introducing ether groups into alkyl side chains can reduce IL microbial toxicity. ${ }^{68}$ In an effort to decrease the microbial toxicity of the mandelic acid derived ILs 1-10, the replacement of the alkyl side chains with ethereal side chains was considered. However, as it is recommended that both methoxy- and ethoxy-terminal substitution are avoided with the aim of preventing any concurrent decrease<smiles></smiles>

23, $6 \%$<smiles></smiles>

24, $31 \%$

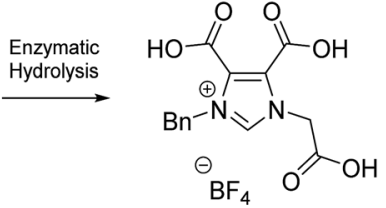

23 PTP

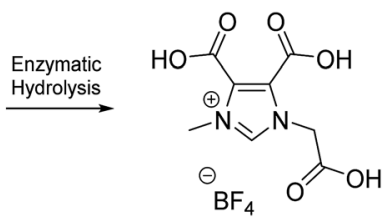

24 PTP
Fig. 3 Percentage biodegradation results for pyridinium ILs with benzyl (23) and methyl (24) analogues synthesised by Gore et al. ${ }^{36}$ and the PTPs (23 PTP and 24 PTP). Biodegradation values assessed by the $\mathrm{CO}_{2}$ Headspace test ISO 14593. 

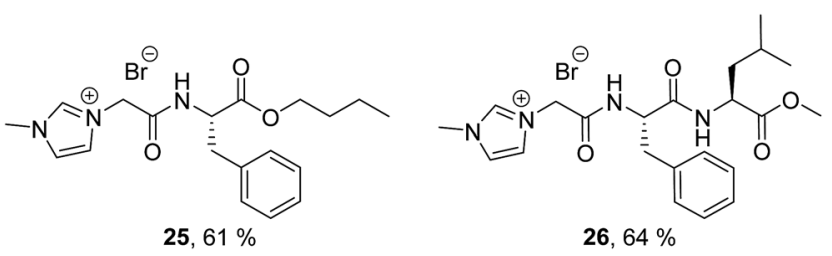

26, $64 \%$

Fig. 4 Percentage biodegradation results for pyridinium ILs (25 and 26) synthesised by Coleman et al. ${ }^{34}$ Biodegradation values assessed by the $\mathrm{CO}_{2}$ Headspace test ISO 14593.

in IL biodegradability, ${ }^{68}$ those ether derivatives were not selected as target ILs for this study.

The increase in IL toxicity that is observed with increasing alkyl chain length of the IL cation has been widely published. ${ }^{7,10,11,15,16,69,70}$ This observation presented for the mandelic acid derived ILs 1-10, where IL toxicity increased in the order methyl ester $<$ ethyl ester $<n$-butyl ester/amide. Again, this is linked to an increase in IL lipophilicity where ILs with longer alkyl chain lengths have a higher lipophilicity and a greater interaction with cell membranes.

A quantitative structure-property relationship (QSPR) assessment carried out by Couling et al. for the marine bacteria Vibrio fischeri suggested that imidazolium ILs are more toxic than pyridinium ILs. ${ }^{69}$ They propose this is due to an increased number of nitrogen atoms with two aromatic and one single bond in the imidazolium ring. However, in the work presented herein no clear conclusion could be drawn on the effect of the imidazolium and pyridinium headgroups on the microbial toxicity of the mandelic acid derived ILs 1-10.

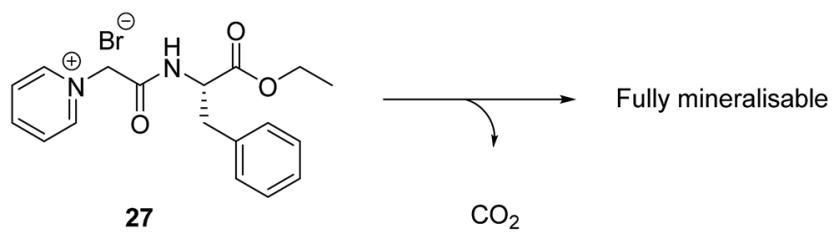

$63 \%$ in 28 days

$76 \%$ in 42 days

Fig. 5 Percentage biodegradation results for fully mineralisable pyridinium IL (27) synthesised by Jordan et al. ${ }^{35}$ and Haiß $\beta$ et al. ${ }^{37}$ Biodegradation values assessed by the CBT OECD 301D.

\section{Biodegradation studies}

The aerobic biodegradability of the ten mandelic acid derived ILs 1-10 (biodegradation data, Table 4) were evaluated based on the Closed Bottle test (CBT) (OECD 301D) (see ESI $\dagger$ for method). ${ }^{71}$ This test is the most stringent of the OECD series as it works with the lowest density and functional diversity of bacteria. It was selected to make sure that any compounds which are classified as readily biodegradable are biodegraded everywhere in the aquatic environment. The validity of the test run was confirmed by satisfying the criteria for validity according to the test guidelines, which includes the reference substance sodium acetate reaching $>60 \%$ biodegradation within 14 days and the concentration of oxygen in the bottles not decreasing below $0.5 \mathrm{mg} \mathrm{\textrm {L } ^ { - 1 }}$ at any time.

A percentage of theoretical ester/amide biodegradation can be calculated for a compound by assuming that all the ester/ amide carbons in the molecule are completely mineralised, i.e. broken down to carbon dioxide and water during biodegradation (oxidation of nitrogen by nitrification has to also be taken into account when calculating theoretical values of oxygen demand). The calculated theoretical ester/amide biodegradation values can then be compared to the experimental biodegradation values. If the values are similar it is reasonable to assume that biodegradation of the compound is probably occurring at the ester/amide. Significantly lower theoretical values than the experimental ones would suggest that other parts of the molecule are also likely to be biodegrading. Theoretical values that are significantly higher than the experimental values would suggest the ester/amide bond is likely not biodegrading, or only partially biodegrading. The theoretical ester/amide biodegradation calculations for ILs 1-10 were performed and the values were compared to the experimental results obtained in the CBT (Table 4).

\section{Biodegradation screening results}

The results show that none of the ILs reached $>60 \%$ biodegradation in 28 days and thus cannot be classified as readily biodegradable by the OECD 301D CBT (Table 4). The 3-(ethoxycarbonyl)pyridinium $n$-butyl ester IL (8) had the highest level of biodegradation (31\% in 28 days). The 1-methylimidazolium $n$ butyl amide IL (9) and pyridinium $n$-butyl amide IL (10) did not biodegrade at all under the test conditions ( $0-1 \%$ in 28 days). The percentage biodegradation reached by each IL in the test<smiles>[R]C(C(=O)OCC)n1cccc1Br</smiles>

$\mathrm{R}=\mathrm{H}, \mathbf{2 8}, 87 \%($ Ref 73$)$

$\mathrm{R}=\mathrm{Ph}, \mathbf{4}, 16 \%$

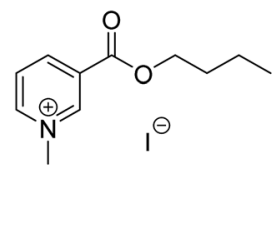

$29,72 \%(\operatorname{Ref} 73)$

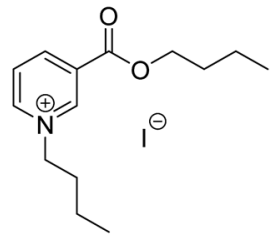

$30,84 \%(\operatorname{Ref} 73)$<smiles></smiles>

$8,31 \%$

Fig. 6 Percentage biodegradation results for pyridinium (28) and nicotinic acid derived (29 and 30) ILs synthesised by Harjani et al. ${ }^{73}$ and mandelic acid derived ILs 4 and 8 . Biodegradation values assessed by the CBT OECD 301D. 

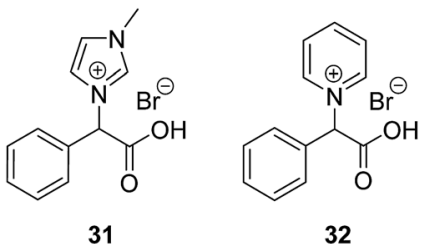

32<smiles>COc1ccc[n+](C(C(=O)O)c2ccccc2)c1</smiles>

33



34
Fig. 7 Structures of the PTPs for ILs 1-8 (31-34).

can be rationalised as biodegradation of the ester/amide groups (side chain) of the ILs. It is well known that ester groups can facilitate high levels of biodegradability and are often introduced into compounds to increase their levels of biodegradability, ${ }^{68,72}$ although there are some exceptions. ${ }^{35}$ IL 8 contains the largest percentage of ester groups per molecule, with both an ethyl and $n$-butyl ester, thus it is not surprising that it shows the highest level of biodegradation in the CBT. The CBT results also show, as expected, that the level of biodegradation increased as the ester chain length increased. This trend is observed for the 1-methylimidazolium ILs 1, 3 and 5 (5, 20, 27\% biodegradation in 28 days, for methyl, ethyl and $n$-butyl esters respectively) and the pyridinium ILs 2,4 and 6 (8, 16, 21\% biodegradation in 28 days, for methyl, ethyl and $n$-butyl esters respectively). Amide moieties have been shown in the literature to have poor levels of biodegradation, ${ }^{12,13,68}$ thus the low levels of biodegradation observed for the 1-methylimidazolium (9) and a pyridinium (10) $n$-butyl amide ILs in the CBT ( 0 and $1 \%$ biodegradation in 28 days, respectively) are expected. The CBT results of the $n$-butyl ester ILs 5-8 were in the range $21-31 \%$. This narrow range of values does not support a detailed analysis of the effect of the headgroup (pyridinium, 3-methoxy pyridinium, 1-methylimidazolium and 3-(ethoxycarbonyl)pyridinium) on biodegradation.

This class of compounds (1-10) presents with low levels of biodegradation similar to the benzylimidazolium ILs previously reported by Gore et al. ${ }^{36}$ Benzylimidazolium ILs containing amide groups showed very low levels of biodegradation (0-4\%), a similar result to the amide ILs $\mathbf{9}$ and $\mathbf{1 0}$ reported herein. Biodegradation of a benzylpyridinium IL was also shown to increase with the introduction of an ethyl ester group (by 23\%), a result which was also observed in this study for IL 8. A lower

Table 5 PTPs for ILs 1-8 (31-34)

\begin{tabular}{ll}
\hline Parent IL & PTPs \\
\hline $1,3,5$ & 31 \\
$2,4,6$ & 32 \\
7 & 33 \\
8 & 34
\end{tabular}

level of biodegradation ( $\mathrm{CO}_{2}$ Headspace test ISO 14593) was published by Gore et al. for the benzylimidazolium IL 23 (6\%), compared to the methylimidazolium IL 24 (31\%). We propose this is in part due to a higher share of carbon content of the proposed transformation product (PTP) of IL $23(23=18 \mathrm{C} v s .23$ $\mathrm{PTP}=14 \mathrm{C}, 22 \%$ decrease in $\mathrm{C})$ compared to $24 \mathrm{PTP}(24=12 \mathrm{C}$ vs. $24 \mathrm{PTP}=8 \mathrm{C}, 33 \%$ decrease in $\mathrm{C}$ ), which are both assumed to persist (Fig. 3). While hydrolysis of all three ester groups in both ILs 23 and 24 to give the fully hydrolysed 23 PTP and 24 PTP is reasonable under the test conditions, only the biodegradation value for IL 24 (31\%) supports this complete ester hydrolysis. The biodegradation of IL 23 (6\%) is so low that significant biotic ester hydrolysis cannot be stated. A comprehensive LC-MS study would be required to confirm the structure of transformation products and was beyond the scope of the study. In contrast to the result reported herein are the high levels of biodegradation reported by Coleman et al. ${ }^{34}$ (Fig. $4, \mathrm{CO}_{2}$ Headspace test ISO 14593), Jordan et al. ${ }^{35}$ and Hai $\beta$ et al. ${ }^{37}$ (Fig. 5, CBT) for several phenyl containing amino acid ILs.

The effect of a phenyl group attached to the same carbon atom as the headgroup can be evaluated by comparing the biodegradation of ILs 4 and 8 to previously reported ILs with pyridinium headgroups (28) and nicotinic acid derived headgroups (29 and 30) (Fig. 6). ${ }^{73}$ The nicotinic acid derived IL (8) presented herein gave significantly lower levels of biodegradation $(31 \%)$ than the readily biodegradable nicotinic acid derived ILs 29 and 30 (72 and 84\% respectively). Also, pyridinium IL 4 gave significantly lower levels of biodegradation (16\%) than the comparative readily biodegradable pyridinium IL 28 (87\%). This suggests that $\alpha$-substitution of the $\mathrm{N}$-heterocycle with a phenyl group (from the mandelic acid starting material) has a significant negative impact on the biodegradability of the ILs. We propose this is a new rule of thumb to be considered when designing biodegradable compounds. It should also be noted that even lower levels of biodegradation were recorded for the amide ILs 9 and 10, which were expected for reasons previously described.

The comparison of the theoretical ester/amide biodegradation values to the experimental values for ILs 1-10 (Table 4) show that a good prediction for the ester ILs 1-8 is obtained. This analysis allows for the conclusion that the biodegradation of the ester ILs is most likely occurring only at the ester bonds. A clear trend is observed across the series in the order of methyl ester ILs (5-8\% biodegradation), ethyl ester ILs (16-20\% biodegradation), $n$-butyl ester ILs (21-27\% biodegradation) and ethyl $/ n$-butyl ester IL 8 (31\% biodegradation). When considering the confidence levels of the test, even a prediction of $6 \%$ lower theoretical biodegradation compared to that observed experimentally (IL 3) is likely not significant enough to suggest that additional parts of the molecule (i.e. the 1-methylimidazolium ring) are breaking down. This conclusion is additionally supported by the literature which shows that 1methylimidazolium based ILs are often poorly biodegradable. ${ }^{74}$

The calculated theoretical biodegradation values for the 1methylimidazolium $n$-butyl amide IL (9) and the pyridinium $n$ butyl amide IL (10) are much higher than the biodegradation results obtained experimentally $(+25$ and $+22 \%$ respectively). 
The calculation is made assuming that biodegradation of the amide is occurring; however, from the experimental values we can see that for IL $\mathbf{9}$ and $\mathbf{1 0}$ no biodegradation occurred at all under the conditions of the CBT in the 28 day period. This is in accordance with literature that reports amides to have poor levels of biodegradation. ${ }^{68}$ Thus, the calculation overestimates the level of biodegradation expected for the amide ILs as the experiments show that the amides did not biodegrade under the CBT conditions over 28 days.

\section{Biodegradation proposed transformation products}

When a compound biodegrades a number of biodegradation transformation products are produced that might not be accessible to further biodegradation (so called persistent transformation products). ${ }^{\mathbf{1 4}}$ The PTPs of ILs 1-8 formed by ester breakdown are the carboxylic acid derivatives of the parent ILS (23-26) (Fig. 7 and Table 5). Amide ILs 9 and 10 give the same PTPs as the ester ILs (31 and 32 respectively), although no biodegradation was observed in the CBT. Alkylamines have previously shown high levels of degradation in biodegradation tests (oxygen consumption, colorimetric, total organic carbon (TOC) and $\mathrm{CO}_{2}$ production measurements). ${ }^{64}$ We propose that if amide hydrolysis had occurred the biodegradation of $n$-butylamine would have been detected by the CBT. In our test there is no evidence of this breakdown. Transformation products can be detected after biodegradation studies by carrying out LC-MS, MS/MS, LC-HRMS and/or NMR analysis on the resultant biodegradation stream..$^{37,75,76}$ An analysis of the toxicity of the

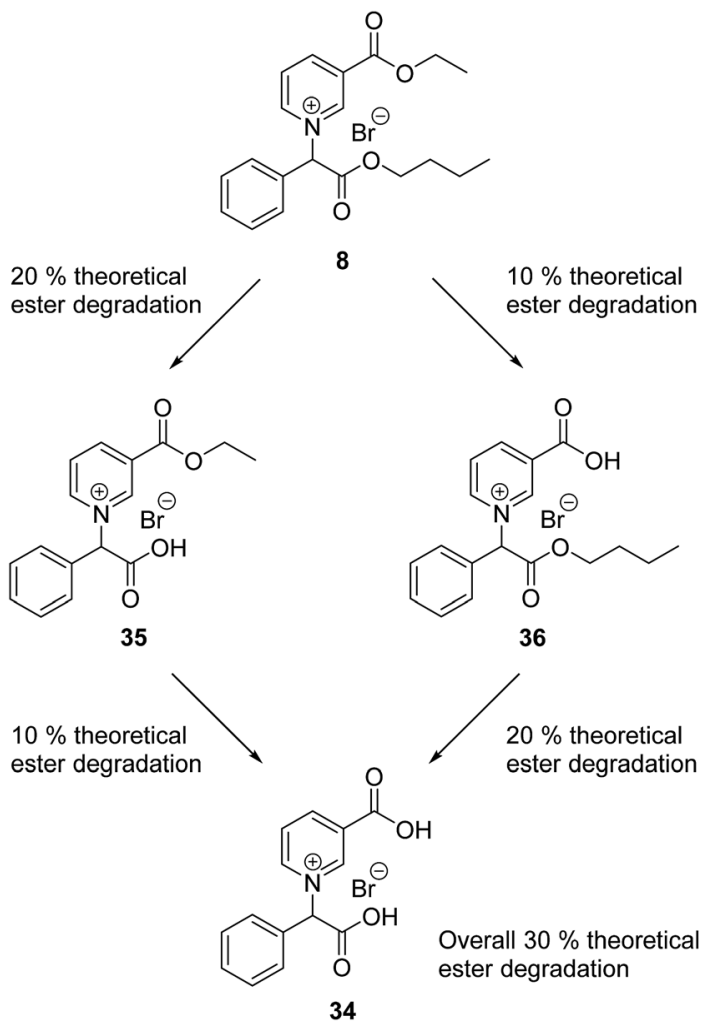

Scheme 3 Proposed biodegradation pathways for IL 8 . transformation products is also always recommended as they may be more toxic than the parent compounds. ${ }^{77}$ For toxicity studies to be undertaken, synthesis of the individual PTPs needs to be carried out. However, with the same PTPs presenting for multiple ILs, only a small number of compounds would need to be synthesised to obtain toxicity/biodegradation data on the transformation products for multiple parent compounds.

The 3-(ethoxycarbonyl)pyridinium $n$-butyl ester IL (8) contains two ester groups which may have different rates of biodegradation in the CBT, leading to the production of two additional transformation products (35 and 36) (Scheme 3). A comparison of the theoretical ester/amide biodegradation of IL 8 to the experimental biodegradation (30 and 31\% respectively) shows that they are very similar. This suggests that the biodegradation of IL $\mathbf{8}$ did not stop at either of the mono ester transformation products ( 35 and 36) during the 28 day period of the CBT. Both biodegradation pathways may have the same kinetic rate leading to the predominant transformation product 34 (Scheme 3) at the end of the CBT. However, a more detailed LC-HRMS study would be required to determine which of the pathways are followed.

\section{Conclusion}

A series of ten bromide ILs (1-10) derived directly from the biorenewable natural product mandelic acid was synthesised. The series was selected based on diverse structural features (including $n$-alkyl chains, ester/amide bonds and various $\mathrm{N}$ heterocyclic headgroups), thus allowing for the investigation of their effect on IL toxicity and biodegradation. None of the ILs showed high antimicrobial activity to the twenty bacterial and fungal strains screened as a preliminary toxicity assay. However, moderate toxicity was observed for the 1-methylimidazolium ethyl ester (3) against several of the bacterial strains. Subsequent $\mathrm{IC}_{50}$ determination showed that the majority of the ILs presented with low toxicity towards one Gram-positive bacterial strain and four Gram-negative bacterial strains when high IL concentrations (up to $200 \mathrm{mM}$ ) were evaluated. IL toxicity across all bacterial strains increased as the alkyl chain length increased in the order methyl ester $<$ ethyl ester $<n$-butyl ester/ amide. Despite observing in general a higher antimicrobial activity for the ILs (1-10) compared to the previously synthesised highly oxygenated mandelic acid derived ILs (19-22), it is a substantial positive result that the ILs herein do not represent a large increase in the level of inhibition. Low toxicity ILs (1-10) were synthesised in a shorter and more efficient synthesis directly from mandelic acid (c.f. 19-22) satisfying the $4^{\text {th }}$ and $7^{\text {th }}$ principles of green chemistry: designing safer chemicals and the use of renewable feedstocks (respectively).

The biodegradation studies of the ILs in the CBT showed biodegradation in the range of $5-31 \%$ in 28 days for the mandelic acid derived ester ILs (1-8). The mandelic acid derived amide ILs $\mathbf{9}$ and $\mathbf{1 0}$ demonstrated no biodegradation in the CBT ( 0 and $1 \%$ in 28 days, respectively). The CBT results of the $n$ butyl ester ILs 5-8 were in the narrow range (21-31\%) which does not support a detailed analysis of the effect of the 
headgroup. The biodegradation pathway proposed for the ILs is through ester alkyl chain biodegradation to a carboxylic acid derivative. This conclusion is based on previous results in the literature, and was reinforced by comparing the results of a theoretical ester/amide biodegradation calculation to the results obtained in the CBT.

An overall goal is to develop ILs which biodegrade fully (i.e. mineralise completely) by breaking down via transient transformation products, and to expand our understanding of rules of thumb to design biodegradable chemicals. As we and others work towards this goal, persistent transformation products have been proposed and identified. ${ }^{\mathbf{1 3 , 3 5 , 3 7}}$ It is an ongoing challenge to design from the outset a series of compounds (which includes predicted transformation products) that lead to the greatest optimisation of a structure activity relationship (SAR) for biodegradation (mineralisation).

Biodegradation studies of ILs containing a phenyl ring demonstrate that examples are known which can pass readily biodegradable tests $(\mathbf{2 5}, \mathbf{2 6}, \mathbf{2 8}, \mathbf{2 9}, \mathbf{3 0})$, can be classed as mineralisable (27), or not pass the readily biodegradable tests (23). The mandelic acid derived ILs (1-10) fall into the latter category and can be included in the rules of thumb for the design of biodegradable ILs.

\section{Acknowledgements}

The authors HP, AHeise and NG have received funding from the European Union's Seventh Framework Programme for research, technological development and demonstration under grant agreement No. 289253. NG acknowledges funding from the European Union's Seventh Framework Programme for research, technological development and demonstration under grant agreement \#621364 (TUTIC-Green). Antimicrobial screening (MS) was supported by Project No. 15-07332S of the Czech Science Foundation. The authors also wish to also acknowledge the contribution of Florian Gross for antimicrobial screening carried out at Dublin City University.

\section{References}

1 N. V. Plechkova and K. R. Seddon, Chem. Soc. Rev., 2008, 37, 123.

2 S. Sowmiah, V. Srinivasadesikan, M. C. Tseng and Y. H. Chu, Molecules, 2009, 14, 3780.

3 P. T. Anastas and J. C. Warner, Green Chemistry: Theory and Practice, Oxford University Press, New York, 1998.

4 M. T. Garcia, N. Gathergood and P. J. Scammells, Green Chem., 2005, 7, 9.

5 N. Gathergood, P. J. Scammells and M. T. Garcia, Green Chem., 2006, 8, 156.

6 N. Gathergood, M. T. Garcia and P. J. Scammells, Green Chem., 2004, 6, 166.

7 J. Pernak, K. Sobaszkiewicz and I. Mirska, Green Chem., 2003, 5,52 .

8 J. Ranke, K. Molter, F. Stock, U. Bottin-Weber, J. Poczobutt, J. Hoffmann, B. Ondruschka, J. Filser and B. Jastorff, Ecotoxicol. Environ. Saf., 2004, 58, 396.
9 M. Petkovic, K. R. Seddon, L. P. N. Rebelo and C. S. Pereira, Chem. Soc. Rev., 2011, 40, 1383.

10 J. Ranke, S. Stolte, R. Stormann, J. Arning and B. Jastorff, Chem. Rev., 2007, 107, 2183.

11 T. P. T. Pham, C.-W. Cho and Y.-S. Yun, Water Res., 2010, 44, 352.

12 D. Coleman and N. Gathergood, Chem. Soc. Rev., 2010, 39, 600.

13 A. Jordan and N. Gathergood, Chem. Soc. Rev., 2015, 44, 8200. 14 S. Stolte, S. Steudte, A. Igartua and P. Stepnowski, Curr. Org. Chem., 2011, 15, 1946.

15 K. S. Egorova and V. P. Ananikov, ChemSusChem, 2014, 7, 336.

16 M. Amde, J.-F. Liu and L. Pang, Environ. Sci. Technol., 2015, 49, 12611.

17 X. D. Hou, Q. P. Liu, T. J. Smith, N. Li and M. H. Zong, PLoS One, 2013, 8, e59145.

18 Q.-P. Liu, X.-D. Hou, N. Li and M.-H. Zong, Green Chem., 2012, 14, 304.

19 N. Ferlin, M. Courty, A. N. Van Nhien, S. Gatard, M. Pour, B. Quilty, M. Ghavre, A. Haiss, K. Kummerer, N. Gathergood and S. Bouquillon, RSC Adv., 2013, 3, 26241. 20 N. Ferlin, M. Courty, S. Gatard, M. Spulak, B. Quilty, I. Beadham, M. Ghavre, A. Haiss, K. Kummerer, N. Gathergood and S. Bouquillon, Tetrahedron, 2013, 69, 6150.

21 S. Kirchhecker, S. Troger-Muller, S. Bake, M. Antonietti, A. Taubert and D. Esposito, Green Chem., 2015, 17, 4151.

22 C. A. Fewson, FEMS Microbiol. Lett., 1988, 54, 85.

23 D. J. D. Hockenhull, A. D. Walker, G. D. Wilkin and F. G. Winder, Biochem. J., 1952, 50, 605.

24 A. F. Landymore, N. J. Antia and G. H. N. Towers, Phycologia, 1978, 17, 319.

25 J. W. Walker and V. K. Krieble, J. Chem. Soc., Trans., 1909, 95, 1369.

26 E. Micklander, L. Brimer and S. B. Engelsen, Appl. Spectrosc., 2002, 56, 1139.

27 P. D. A. Singh, J. R. Jackson and S. P. James, Biochem. Pharmacol., 1985, 34, 2207.

28 M. J. R. Nout, G. Tuncel and L. Brimer, Int. J. Food Microbiol., 1995, 24, 407.

29 K. Yamamoto, K. Oishi, I. Fujimatsu and K. Komatsu, Appl. Environ. Microbiol., 1991, 57, 3028.

30 Z. Wang, in Comprehensive Organic Name Reactions and Reagents, John Wiley \& Sons, Inc., 2010, vol. 2, ch. 408, pp. 1816-1819.

31 Z. Sun, Y. Ning, L. Liu, Y. Liu, B. Sun, W. Jiang, C. Yang and S. Yang, Microb. Cell Fact., 2011, 10, 71.

32 S. P. M. Ventura, M. Gurbisz, M. Ghavre, F. M. M. Ferreira, F. Goncalves, I. Beadham, B. Quilty, J. A. P. Coutinho and N. Gathergood, ACS Sustainable Chem. Eng., 2013, 1, 393.

33 J. Ranke, A. Muller, U. Bottin-Weber, F. Stock, S. Stolte, J. Arning, R. Stormann and B. Jastorff, Ecotoxicol. Environ. Saf., 2007, 67, 430.

34 D. Coleman, M. Spulak, M. T. Garcia and N. Gathergood, Green Chem., 2012, 14, 1350. 
35 A. Jordan, A. Haiß, M. Spulak, Y. Karpichev, K. Kummerer and N. Gathergood, Green Chem., 2016, 18, 4374.

36 R. G. Gore, L. Myles, M. Spulak, I. Beadham, T. M. Garcia, S. J. Connon and N. Gathergood, Green Chem., 2013, 15, 2747.

37 A. Haiß, A. Jordan, J. Westphal, E. Logunova, N. Gathergood and K. Kummerer, Green Chem., 2016, 18, 4361.

38 R. S. Boethling, E. Sommer and D. DiFiore, Chem. Rev., 2007, 107, 2207.

39 S. I. T. Kennedy and C. A. Fewson, J. Gen. Microbiol., 1968, 53, 259.

40 M. Jamaluddin, P. V. S. Rao and C. S. Vaidyanathan, J. Bacteriol., 1970, 101, 786.

41 C. S. Harwood and R. E. Parales, Annu. Rev. Microbiol., 1996, $50,553$.

42 S. G. Bhat and C. S. Vaidyanathan, J. Bacteriol., 1976, 127, 1108.

43 A. Kowalkowska and A. Jończyk, Synth. Commun., 2011, 41, 3308.

44 B. Riegel and H. Wittcoff, J. Am. Chem. Soc., 1946, 68, 1913. 45 C. Zhang, H. Ito, Y. Maeda, N. Shirai, S.-i. Ikeda and Y. Sato, J. Org. Chem., 1999, 64, 581.

46 Y. Su, L. Zhang and N. Jiao, Org. Lett., 2011, 13, 2168.

47 Z. Wang, in Comprehensive Organic Name Reactions and Reagents, John Wiley \& Sons, Inc., New Jersey, 2010, vol. 1, ch. 239, pp. 1095-1097.

48 O. Kuisle, E. Quiñoá and R. Riguera, J. Org. Chem., 1999, 64, 8063.

49 N. Shakya, K. K. Roy and A. K. Saxena, Bioorg. Med. Chem., 2009, 17, 830.

50 S.-S. Weng, H.-C. Li and T.-M. Yang, RSC Adv., 2013, 3, 1976.

51 G. C. Lloyd-Jones, P. D. Wall, J. L. Slaughter, A. J. Parker and D. P. Laffan, Tetrahedron, 2006, 62, 11402.

52 B. R. Kim, H.-G. Lee, S.-B. Kang, G. H. Sung, J.-J. Kim, J. K. Park, S.-G. Lee and Y.-J. Yoon, Synthesis, 2012, 44, 42.

53 L. J. Gooßen, D. M. Ohlmann and P. P. Lange, Synthesis, 2009, 2009, 160.

54 P. C. Astles, T. J. Brown, F. Halley, C. M. Handscombe, N. V. Harris, T. N. Majid, C. McCarthy, I. M. McLay, A. Morley, B. Porter, A. G. Roach, C. Sargent, C. Smith and R. J. A. Walsh, J. Med. Chem., 2000, 43, 900.

55 K. Ohno, Y. Ma, Y. Huang, C. Mori, Y. Yahata, Y. Tsujii, T. Maschmeyer, J. Moraes and S. Perrier, Macromolecules, 2011, 44, 8944.

56 K. R. Seddon, Presented in part at the COIL-6, Jéju, South Korea, 2015.

57 K. Kümmerer, A. Al-Ahmad and A. Henninger, Acta Hydrochim. Hydrobiol., 2002, 30, 171.
58 M27-A3, Reference Method for Broth Dilution Antifungal Susceptibility Testing of Yeasts; Approved Standard Institute, Clinical and Laboratory Standards Institute, Wayne, PA, 3rd edn, 2008.

59 M38-A2, Reference Method for Broth Dilution Antifungal Susceptibility Testing of Filamentous Fungi; Approved Standard Institute, Clinical and Laboratory Standards Institute, Wayne, PA, 2nd edn, 2008.

60 M. Ghavre, PhD thesis, Dublin City University, 2012.

61 M. Gurbisz, PhD thesis, Dublin City University, 2012.

62 M. C. Bubalo, K. Radosevic, I. R. Redovnikovic, J. Halambek and V. G. Srcek, Ecotoxicol. Environ. Saf., 2014, 99, 1.

63 C.-W. Cho, Y.-C. Jeon, T. P. T. Pham, K. Vijayaraghavan and Y.-S. Yun, Ecotoxicol. Environ. Saf., 2008, 71, 166.

64 K. Yoshimura, S. Machida and F. Masuda, J. Am. Oil Chem. Soc., 1980, 57, 238.

65 H. Sütterlin, R. Alexy, A. Coker and K. Kümmerer, Chemosphere, 2008, 72, 479.

66 T. Ikeda, H. Yamaguchi and S. Tazuke, J. Bioact. Compat. Polym., 1990, 5, 31.

67 D. B. Zhao, Y. C. Liao and Z. D. Zhang, Toxicity of ionic liquids, Clean: Soil, Air, Water, 2007, 35(1), 42-48.

68 S. Morrissey, B. Pegot, D. Coleman, M. T. Garcia, D. Ferguson, B. Quilty and N. Gathergood, Green Chem., 2009, 11, 475.

69 D. J. Couling, R. J. Bernot, K. M. Docherty, J. K. Dixon and E. J. Maginn, Green Chem., 2006, 8, 82.

70 X. F. Wang, C. A. Ohlin, Q. H. Lu, Z. F. Fei, J. Hu and P. J. Dyson, Green Chem., 2007, 9, 1191.

71 Organization for Economic Cooperation and Development (OECD), OECD Guideline for Testing of Chemicals; Ready Biodegradability, Paris, July 1992.

72 S. Morrissey, PhD Thesis, Dublin City University, 2008.

73 J. R. Harjani, R. D. Singer, M. T. Garcia and P. J. Scammells, Green Chem., 2009, 11, 83.

74 S. Stolte, S. Abdulkarim, J. Arning, A. K. Blomeyer-Nienstedt, U. Bottin-Weber, M. Matzke, J. Ranke, B. Jastorff and J. Thoming, Green Chem., 2008, 10, 214.

75 K. M. Docherty, M. V. Joyce, K. J. Kulacki and C. F. Kulpa, Green Chem., 2010, 12, 701.

76 Y. Deng, I. Beadham, M. Ghavre, M. F. Costa Gomes, N. Gathergood, P. Husson, B. Legeret, B. Quilty, M. Sancelme and P. Besse-Hoggan, Green Chem., 2015, 17, 1479.

77 A. B. A. Boxall, C. J. Sinclair, K. Fenner, D. Kolpin and S. J. Maud, Environ. Sci. Technol., 2004, 38, 368a. 